\title{
Observations of ice nuclei and heterogeneous freezing in a Western Pacific extratropical storm
}

\author{
J. L. Stith ${ }^{1}$, C. H. Twohy ${ }^{2}$, P. J. DeMott ${ }^{3}$, D. Baumgardner ${ }^{4}$, T. Campos ${ }^{1}$, R. Gao ${ }^{5}$, and J. Anderson ${ }^{6}$ \\ ${ }^{1}$ National Center for Atmospheric Research, Boulder, Colorado, USA \\ ${ }^{2}$ College of Oceanic and Atmospheric Sciences, Oregon State University, Corvallis, Oregon, USA \\ ${ }^{3}$ Department of Atmospheric Sciences, Colorado State University, Fort Collins, Colorado, USA \\ ${ }^{4}$ Centro de Ciencias de la Atmósfera, Universidad Nacional Autónoma de México, Mexico City, Mexico, USA \\ ${ }^{5}$ Chemical Sciences Division, NOAA Earth System Research Laboratory, Boulder, Colorado, USA \\ ${ }^{6}$ School for Engineering of Matter, Transport and Energy, Tempe, Arizona, USA
}

Received: 16 December 2010 - Published in Atmos. Chem. Phys. Discuss.: 7 January 2011

Revised: 16 June 2011 - Accepted: 17 June 2011 - Published: 1 July 2011

\begin{abstract}
In situ airborne sampling of refractory black carbon (rBC) particles and Ice Nuclei (IN) was conducted in and near an extratropical cyclonic storm in the western Pacific Ocean during the Pacific Dust Experiment, PACDEX, in the spring of 2007. Airmass origins were from Eastern Asia. Clouds associated primarily with the warm sector of the storm were sampled at various locations and altitudes. Cloud hydrometeors were evaporated by a counterflow virtual impactor (CVI) and the residuals were sampled by a single particle soot photometer (SP2) instrument, a continuous flow diffusion chamber ice nucleus detector (CFDC) and collected for electron microscope analysis. In clouds containing large ice particles, multiple residual particles were observed downstream of the CVI for each ice particle sampled on average. The fraction of $\mathrm{rBC}$ compared to total particles in the residual particles increased with decreasing condensed water content, while the fraction of IN compared to total particles did not, suggesting that the scavenging process for $\mathrm{rBC}$ is different than for IN. In the warm sector storm midlevels at temperatures where heterogeneous freezing is expected to be significant (here -24 to $-29^{\circ} \mathrm{C}$ ), IN concentrations from ice particle residuals generally agreed with simultaneous measurements of total ice concentrations or were higher in regions where aggregates of crystals were found, suggesting heterogeneous freezing as the dominant ice formation process in the mid levels of these warm sector clouds. Lower in the storm, at warmer temperatures, ice concentrations were affected by aggregation and were somewhat less than mea-
\end{abstract}

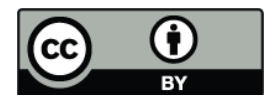

Correspondence to: J. L. Stith (stith@.ucar.edu) sured IN concentrations at colder temperatures. The results are consistent with ice particles forming at storm mid-levels by heterogeneous freezing on IN, followed by aggregation and sedimentation to lower altitudes. Compositional analysis of the aerosol and back trajectories of the air in the warm sector suggested a possible biomass burning source for much of the aerosol. Comparison of the particles from the CFDC with the other aerosol in the residuals of ice particles suggested that the largest portion of IN had similar inferred origins (from biomass burning with minor amounts of $\mathrm{rBC}$ ) as the other aerosol, but contained slightly elevated amounts of calcium and less influence from sea salt.

\section{Introduction}

Understanding the origins of ice in storms and the relationship between ice in the clouds and aerosols continues to be a fundamental problem in cloud physics. This is especially important for understanding the possible effects of anthropogenic aerosols on storms and their climatologically significant properties, such as precipitation, storm/cloud lifetimes and cloud optical properties. Dusts and other aerosols from Asia or Africa are known to be a source of both Ice forming Nuclei (IN) and Cloud Condensation Nuclei (CCN), but their impact on storms is not well known. Part of this difficulty is that ice-containing clouds in deep storms probably contain ice from several sources, including homogenous freezing, heterogeneous freezing (via IN), and by secondary production, such as by Hallett-Mossop rime-splintering.

Black carbon (BC) aerosols are of fundamental interest to studies of anthropogenic climate change because of their

Published by Copernicus Publications on behalf of the European Geosciences Union. 
ability to absorb sunlight and the fact that they have a large anthropogenic source through direct emissions from fossil fuels or indirectly through anthropogenic influences on biomass burning. Trans-Pacific transport of $\mathrm{BC}$ from Asia is thought to impact radiative forcing as far away as North America (Hadley et al., 2007). The interaction of BC with clouds is of particular interest, because clouds and precipitation provide a major removal mechanism for $\mathrm{BC}$ and because $\mathrm{BC}$ containing particles may alter the microphysical structure of clouds by acting as cloud CCN or as IN. The inclusion of $\mathrm{BC}$ in liquid or ice particles may also influence the climate impact of clouds (e.g. Jacobson, 2006) by changing their radiative properties.

In spite of the importance of the interactions of $\mathrm{BC}$ with clouds, there are relatively few observations that demonstrate its major pathways for incorporation into clouds. Some BC may be incorporated into clouds through nucleation, with $\mathrm{BC}$ acting as either CCN or IN. For example, Cozic et al. (2008) observed enrichment in the $\mathrm{BC}$ aerosol mass fraction in ice particle residuals, compared to the mass fraction outside of cloud. They suggested that this result might be due to BCcontaining particles acting preferentially as IN. However, Baumgardner et al. (2008) studied northern Pacific cirrus cloud residuals and concluded that inertial scavenging was likely to be more important than nucleation for scavenging BC. A number of other aerosol particles are thought to serve as IN, such as dust particles, which are abundant from Asian sources (e.g. see Stith et al., 2009 and references therein). Particles from biomass burning are an important component of East Asian aerosols (e.g. Seinfeld et al., 2004), but their effects on clouds are poorly known.

In this paper we examine IN in residuals from cloud droplets and ice particles from a large extratropical spring storm in the western North Pacific Ocean and we compare them with other particles and measurements of lightscattering particles and refractory $\mathrm{BC}(\mathrm{rBC})$ made by a single particle soot photometer (SP2). Carbon Monoxide (CO) measurements indicated the presence of pollution from East Asia in the storm. Extensive airborne sampling of both warm and cold clouds associated with the warm front was conducted. In this part of the storm, Hallett-Mossop secondary ice production was not likely, which allowed relatively uncontaminated comparison between IN and measured ice concentrations. Single particle counting of lightscattering particles and refractory $\mathrm{rBC}$ allowed, even in relatively clean conditions, concentrations to be measured on approximately $10 \mathrm{~s}$ time scales or about $2 \mathrm{~km}$ of flight path. Concurrent IN measurements were available and processed for $60 \mathrm{~s}$ time scales $(\sim 12 \mathrm{~km})$ so that we could examine the association between IN, rBC and other aerosol particles at a relatively high spatial resolution compared to the synoptic regions of the storm. Time-integrated filter and impactor samples of aerosols were collected for chemical and morphological analysis to allow the characteristics of the IN to be compared with other aerosols, including rBC.

\section{Venue and instrumentation}

The storm was one of the cases from the Pacific Dust Experiment (PACDEX) during which a series of fourteen research flights were conducted in the April-May 2007 time period to sample pollution and dust outbreaks from East Asia as they interacted with Northern Pacific storms. The experiment, instrumentation, and early results from the project have been described in detail by Stith et al. (2009), so only a brief overview will be provided here.

PACDEX utilized the NSF/NCAR G-V aircraft, to carry a variety of instruments for aerosol and cloud physics measurements. PACDEX instruments used in this study included a modified high speed 64-element Particle Measuring Systems (PMS)-based OAP-2DC optical array instrument (2DC), a DMT Ultra-High Sensitivity Aerosol Spectrometer (UHSAS) used here to measure aerosols between 0.1 and $1.0 \mu \mathrm{m}$, a fast-response dual-column continuous-flow streamwise thermal gradient CCN chamber, a DMT Cloud Droplet Probe (CDP) to measure cloud droplets and aerosols 2-50 $\mu \mathrm{m}$ in diameter, a vacuum UV absorption analyzer for $\mathrm{CO}$ (with precision of $3 \mathrm{ppbv}$ for a $1 \mathrm{~Hz}$ sample rate), and a dual-beam UV-absorption ozone photometer (precision of approximately $1 \mathrm{ppbv}$ at $200 \mathrm{hPa}$ ). Further details on these and the other PACDEX airborne instruments, including references, are provided in Stith et al. (2009).

The 2DC is used here to sample particles that image three or more of the 25 micron diodes (particles greater than about 75 microns). Smaller images are excluded to reduce uncertainties associated with their depth of field. (The CDP provides a qualitative measure of this smaller particle mode for quasi-spherical ice, however. The CDP does not have a shroud, so it is less subject to the overestimating of small ice particle concentrations that occurs with a shrouded instrument like the FSSP due to the shattering of large ice particles on the shroud). Processing of the 2DC imagery to produce hydrometeor concentrations utilized a circle-fit technique with each particle image to determine the size of the particle, which allowed partial images to be analyzed to reconstruct sizes up to about $3 \mathrm{~mm}$. Data were corrected for probe tip shattering using the methods discussed in Field et al. (2006). Data presented here represent $10 \mathrm{~s}$ averages, unless otherwise indicated.

A titanium Counterflow Virtual Impactor (CVI), mounted on the bottom of the G-V fuselage, was used to sample cloud particles above the CVI threshold size of about $5 \mu \mathrm{m}$ aerodynamic diameter. A HIAPER modular inlet (see Stith et al., 2009 for more information on this inlet) was also used outside of cloud to sample aerosols and trace gases. The CVI provided measurements of condensed water content and a stream of the evaporated residual particles for further analyses and characterization by other instruments. The subisokinetic nature of the CVI provides $\sim 50 \times$ enhancement within the sample stream, which allows for improved statistics for low number concentration particles, such as IN. 
The enhancement factor varies with known quantities such as airspeed and sample flow rate and the uncertainty it contributes to measured concentrations is only about $8 \%$ (Twohy et al., 2003).

Large ice crystals are likely to breakup during collection inside the CVI due to inertial stresses when impacting within the slowly moving counterflow region. Crystal breakup (or "shattering") has been shown to affect a variety of cloud physics measurements; see Jensen et al. (2009) for an overview. Large drops have also been shown to produce enhanced concentrations of residual particles during highspeed sampling (Weber et al., 1998; Twohy et al., 2003). Based on the ratio of drag stress to surface energy density (e.g. Schwarzenböck and Heintzenberg, 2000), the threshold breakup size for quasi-spherical ice is expected to be about $70 \mu \mathrm{m}$ diameter under the sampling conditions for this case (airspeed of $200 \mathrm{~m} \mathrm{~s}^{-1}$, pressure of $345 \mathrm{hPa}$, bulk ice surface energy of $120 \mathrm{~g} \mathrm{~s}^{-2}$ ). This corresponds to a Weber number of about 10, where water droplets have been observed to breakup (Pilch and Erdman, 1987; Tarnogrodzki, 1993). Slightly smaller droplets or crystals may survive the virtual impaction at the CVI probe tip, but fragment when they reach the bend where the sample flow is brought into the aircraft (Anderson and Twohy, 1993).

The counterflow characteristics of the CVI mean its aspiration efficiency is relatively sharp; see for example, Schwarzenböck and Heintzenberg (2000). Their calibration using glass beads yielded $84 \%$ collection efficiency of particles $25-30 \%$ larger than the cut size. This corresponds to between 6-7 $\mu \mathrm{m}$ diameter for a nominal $50 \%$ cut size of $5 \mu \mathrm{m}$ as used in PACDEX. Collection efficiency for glass beads used in the calibration studies may be higher than for droplets and ice due to their tendency to bounce off inlet surfaces. However, Glantz et al. (2003) showed that CVI residual number concentrations in stratocumulus cloud were within $75 \%$ of droplet concentrations measured by an FSSP when most of the droplets were larger than the CVI cut size and when drizzle was not present. Measurements with our inlet yield similar results. In this study we compare the CVI data with cloud particles larger than 75 microns, so the sizes of ice particles in our study are well above the size where CVI aspiration efficiency should be a factor. Additionally, concentrations from the CDP suggest that crystals smaller than 75 microns are present in concentrations too low to impact the results significantly (see below). Given the small CVI cut size relative to the measured ice crystal size distribution, CVI aspiration efficiency is expected to be approximately $100 \%$ for ice crystal sizes included in this study.

The particles that we measured in the CVI represent the residuals from the shattered/evaporated ice particles. They are not artifacts in the sense that most of them did not likely originate from the walls of the inlet (see Sect. 6), but the actual concentrations of particles measured from the residuals might certainly be related to the number and sizes of ice fragments produced in the CVI, which limits quantitative analy- sis of the results. Multiple ice fragments from a single ice crystal could produce a significantly larger number of residual aerosol particles than ice particles, if each crystal contains nonvolatile material other than a single solid nucleus. Processes by which this could occur include freezing of large drops containing solute or inclusions distributed throughout their volume, scavenging of interstitial aerosol particles, or even chemical reactions occurring preferentially on the ice surface (Chen and Crutzen, 1994). Several examples of production of multiple particles from single ice crystals are discussed below.

Particles from both inlets were collected for scanning and transmission electron microscopy using the procedures described in Stith et al. (2009) and analyzed for chemical composition using energy-dispersive X-ray spectroscopy (EDS). Under some conditions ice crystals can generate secondary particles by ablating inlet materials (e.g., Murphy et al., 2004; Kojima et al., 2004). Below we utilize EDS to analyze the composition of sampled particles from the CVI for the presence of titanium to determine if these secondary particles might be present in our samples from the CVI.

Particles containing rBC were sampled by a Droplet Measurement Technologies (DMT) single particle soot photometer (SP-2). It measures the refractory component of BC mass and number by laser induced incandescence and particle size by light scattering in the range of 0.08 to $0.3 \mu \mathrm{m}$ for $\mathrm{rBC}$ mass equivalent diameter; however, particles above about $0.19 \mu \mathrm{m}$ saturate the detector and are counted, but are not sized. Particles that are counted are also used to determine a total scattered particle concentration, which is useful to determine the relative fraction of $\mathrm{rBC}$ to total particles counted by the SP2 instrument (particles can also be sized by reference to their optical diameter rather than their mass equivalent diameter).

IN measurements were made with a continuous-flow (icethermal) diffusion chamber (CFDC) as described in Stith et al. (2009). For the case presented in this paper, the CFDC was operated to process sampled aerosol at near and just above water saturation to favor a combination of ice freezing mechanisms, but especially condensation/immersion freezing (DeMott et al., 2010). The ice nucleation mechanisms operative in clouds in this case cannot be discerned by observations of the clouds alone, but condensation and immersion freezing are likely candidates for nucleation mechanisms active for aerosols subject to warm frontal lifting. Based on the discussion in DeMott et al. (2010) and its supporting information, we estimate the counting uncertainty associated with a 60 s running mean while sampling from the CVI (with its associated enhancement factor) to be approximately 0.1 per liter for concentrations of 1 per liter. Dual upstream impactors were used to limit large aerosol particles entering the instrument to aerodynamic diameters smaller than $1.6 \mathrm{mi}-$ crons (for a CFDC sample flow rate of $1 \mathrm{vlpm}$ ). The outlet of the CFDC was fitted with a separate impactor for collecting the ice crystals formed from activated IN and grown to sizes above $\sim 2.3$ microns (aerodynamic diameter) onto electron 


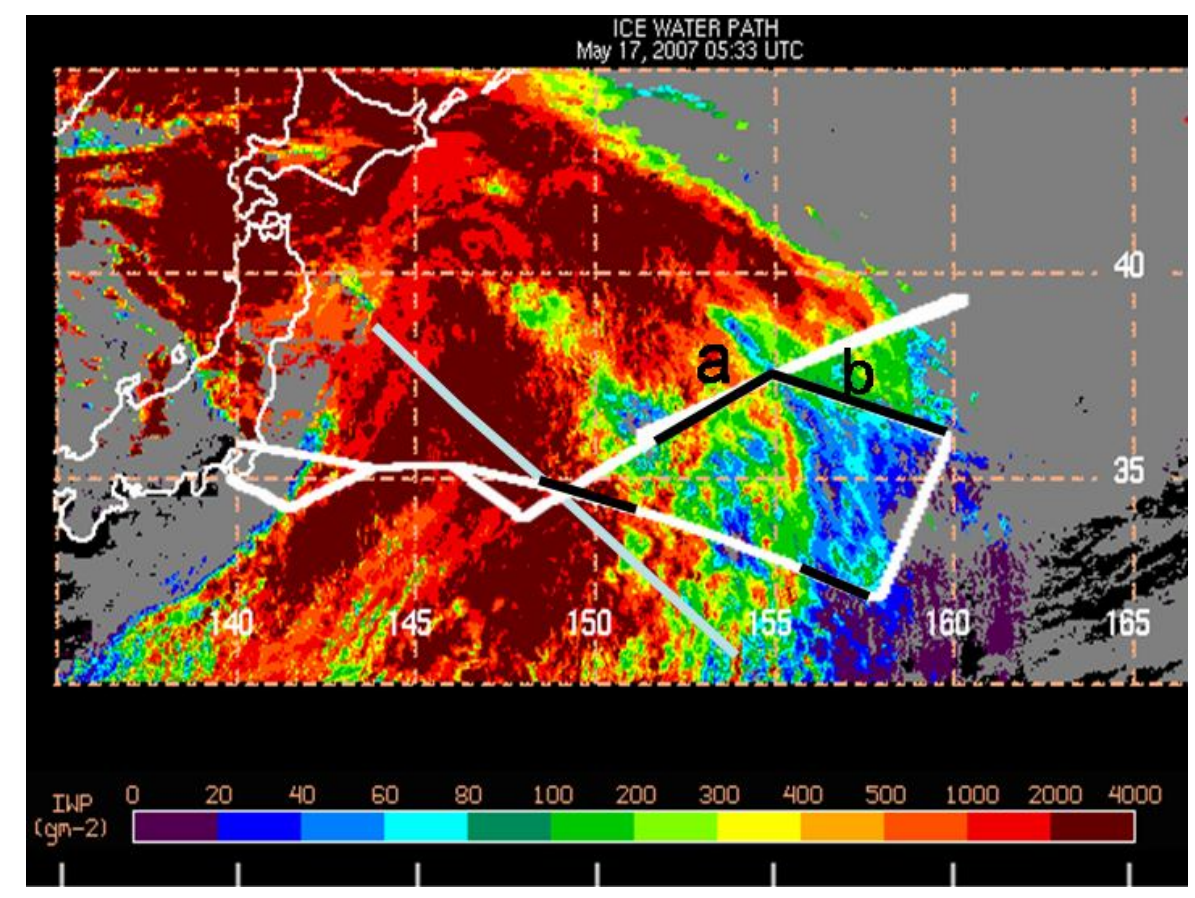

Fig. 1. Flight track of the G-V (white line) overlaid on the ice water path satellite measurements at 05:33. The light blue line represents the approximate location of the near-surface warm front, based on an encounter with it at 08:19 at $2.1 \mathrm{~km}$ altitude. The black segments refer to sampling periods discussed in the text. Image courtesy of NASA Langley Research Center.

microscopy grids for post-analysis. The CFDC is designed to force evaporation of liquid droplets so that only ice crystals are sampled for electron microscopy analysis.

In order to experimentally study the relationship between IN and ice in storms the sampling needs to be isolated to regions where heterogeneous freezing is likely to be active and where the ice in the storm is not contaminated by the other ice-creating mechanisms. Of course, at a given time and sampling location only one ambient temperature and one CFDC chamber temperature and supersaturation is measured, while the actual ice particles that are measured at that location could have formed at higher altitudes (typically colder temperatures) and fallen to the sampling location (or they could have come from below if there are significant updrafts that carry the particles to the sampling location, although significant updrafts were not generally found in the warm sector areas we sampled). We often used a CFDC sampling temperature set near ambient for constant-altitude passes through the clouds, so that the numbers of IN measured should best correspond to single ice crystals forming nearby and are likely a lower limit for concentrations of single crystals that might have formed at colder temperatures in the same airmass that were at the sampling location due to sedimentation. In regions where these single ice crystals aggregate with others, each aggregate ice particle should contain multiple IN.

\section{Storm characteristics and flight procedures}

The storm was sampled on 17 May 2007. It exhibited a classic cold and warm frontal structure that was evident in the satellite image (Fig. 1). The storm region was examined for over eight hours with the G-V, including several descents and ascents to obtain vertical profiles through the cloud and clear air regions and horizontal transects, which were focused primarily on the warm frontal clouds (above the warm frontal surface aloft). In situ identification of the location of the warm frontal region was made by examination of the wind shift and temperature changes consistent with passage through a warm front.

An example of one vertical profile that was taken primarily near the southeastern edge of the storm is provided in Fig. 2. The profile was outside of most of the clouds, except for some thin cirrus in the upper portion of the profile. A clear demarcation in chemical airmass characteristics is evident at the location of the warm front. The properties of the warm sector airmass are unusual because the concentrations of $\mathrm{CO}$ (nearly 200 ppbv in Fig. 2 top) suggests a polluted airmass, yet the levels of ozone (Fig. 2 bottom) and the concentration of aerosols 0.1 to $1.0 \mu \mathrm{m}$ and $\mathrm{rBC}$ (Fig. 2 top and middle) indicates that the warm sector airmass was rather clean in terms of aerosol and ozone. A likely explanation for these somewhat contradictory results is seen by examining the history of the warm sector and cool sector airmasses. Figure 3 provides 

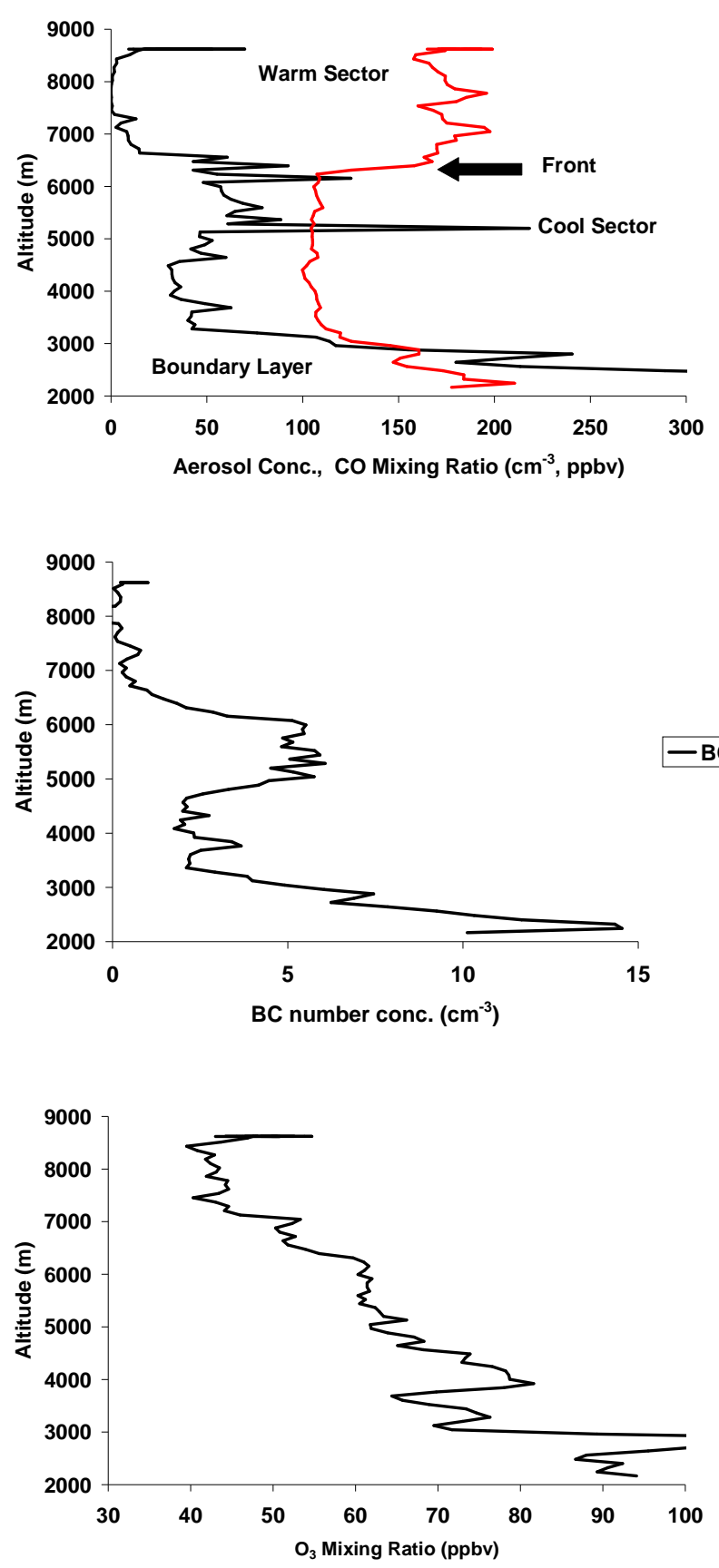

Fig. 2. Vertical profile through the warm frontal region in mostly clear air. Shown in the top figure are aerosol number concentration 0.1 to $1.0 \mu \mathrm{m}$ in size (black line) and CO (red line). (The lower curve for aerosol is cutoff at $300 \mathrm{~cm}^{-3}$, but was over $500 \mathrm{~cm}^{-3}$ at the bottom of the profile). Number concentration of rBC particles (middle figure) and ozone mixing ratio (lower figure). The location for the profile is indicated in the lower right hand dark track in Fig. 1. The location of the warm frontal surface aloft and the different airmass characteristics are indicated in the top figure. a back-trajectory analysis from the NOAA HYSPLIT model (Draxler and Rolph, 2010) for locations in the warm and cool sector airmasses. Figure 4 provides the corresponding model predicted rainfall history. The model suggests that each trajectory passed over different possible pollution sources in East Asia and the warm sector air had more encounters with precipitation than the cool sector air. Thus enhanced scavenging of aerosol particles and ozone precursors seems to be a likely explanation for the somewhat unusual characteristics of the warm sector air, in addition to possible differences in source origin. Extensive biomass burning was present in the source region for the warm sector air (Fig. 3, bottom), suggesting that biomass burning was one source for the aerosols sampled in the warm sector airmass. The biomass burning source is consistent with the compositional analysis of CVI residual particles from within clouds, which is discussed in Sect. 6.

\section{IN and ice particles in the warm-sector clouds: evidence for heterogeneous freezing in the warm-sector cloud}

Simultaneous IN and rBC measurements of CVI residuals are available from a long horizontal transect through the storm at $8.5 \mathrm{~km}$ altitude (Fig. 1 long black track) and at ambient temperatures between -24 and $-29^{\circ} \mathrm{C}$ (with warmer temperatures at the start of the leg and the coldest temperatures at the end). A comparison of the IN concentrations measured from CVI cloud residual particles in the CFDC in the cabin of the aircraft with the ice concentrations measured by the 2DC instrument on the wing is shown in Fig. 5 (liquid water was not found on this pass). During this pass the CDP concentrations started out near the values from the 2DC, but were as much as an order of magnitude lower than the 2DC for most of the pass (not shown). Consequently, the average CDP concentrations (which are included in Fig. 6) suggest the absence of a small ice particle mode for this case. The transect was mostly in the warm sector cloud except after about 05:57 Universal Time Coordinated (UTC), when the upper level front was encountered and the air mass changed from warm sector to cool sector (at the arrow in the lower part of Fig. 5). Size distributions from the two segments of the constant altitude leg (indicated by a and b in Fig. 1) in the warm sector region prior to the warm front are given in Fig. 6. During this pass the CFDC was operated near water saturation. While we attempted to operate the CFDC at temperatures close to the temperature of the ambient air, deviations occurred due to changes in ambient conditions and drift in the chamber control, particularly near the start and end of the run (e.g. Fig. 5 lower figure).

The rather good correlation in much of the pass between IN concentrations from CVI residuals and measured ice particles is noteworthy (although the ratio of IN to ice particle concentration varied from about 0.2 to 10 ), given the 

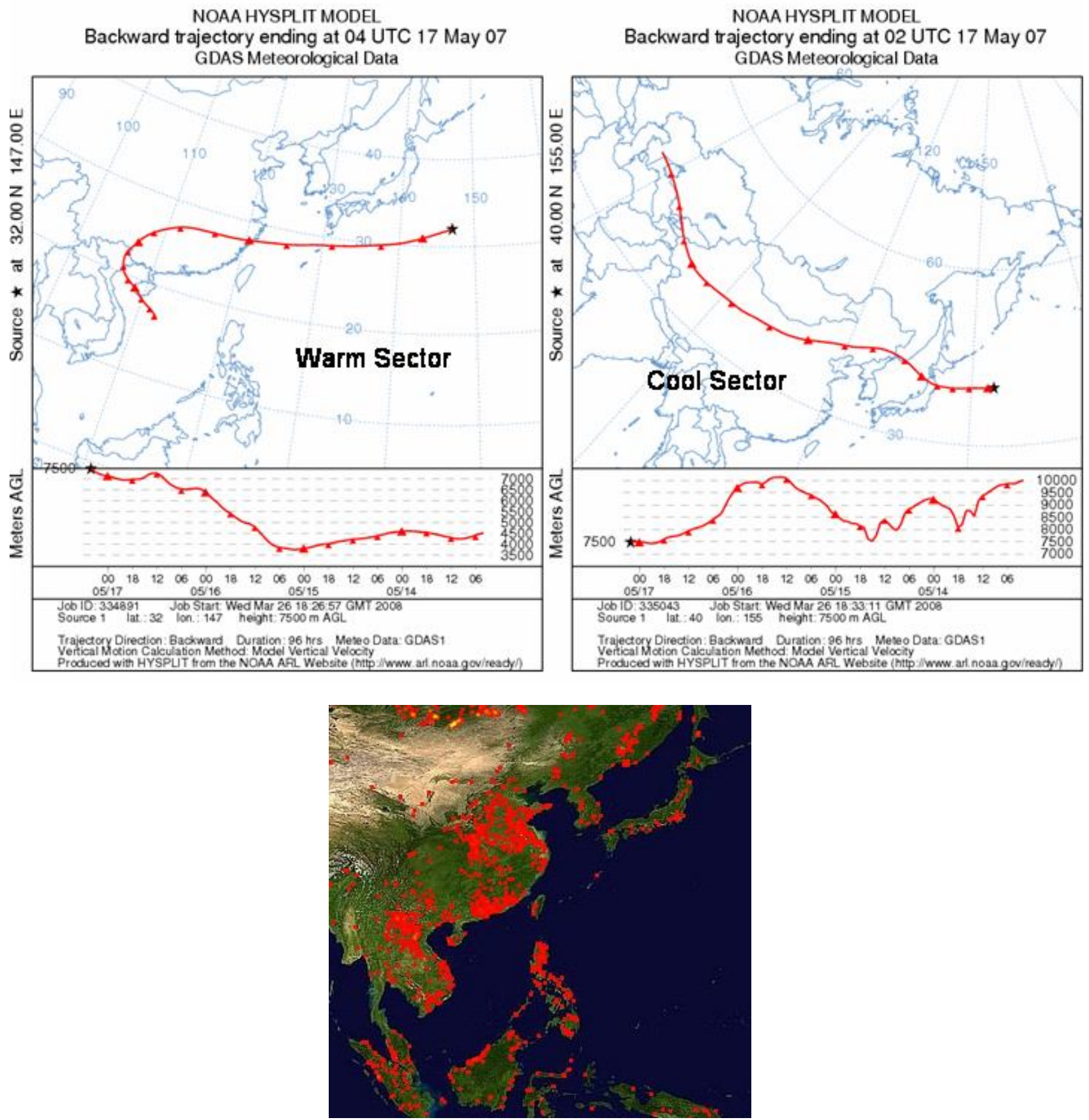

Fig. 3. (Top) NOAA HYSPLIT back trajectories for warm sector air and cool sector air. (Bottom) MODIS fire locations for 11 May through 20 May 2010, (credit: NASA/GSFC, MODIS Rapid Response).

difficulties in correlating ice particles with IN, even in relatively simple clouds such as wave clouds (e.g. Eidhammer et al., 2010). If each IN that nucleated a single crystal survived the fragmentation in the CVI intact and if heterogeneous nucleation was responsible for the observed ice crystals, we would expect there to be a one-to-one correspondence be- tween the observed IN concentrations and the observed ice crystal concentrations, provided the nucleation of the crystals in the natural cloud occurred at temperatures and saturation conditions (near water saturation) similar to those in the CFDC and through the nucleation processes which are represented in the CFDC. Under this scenario, one would also 


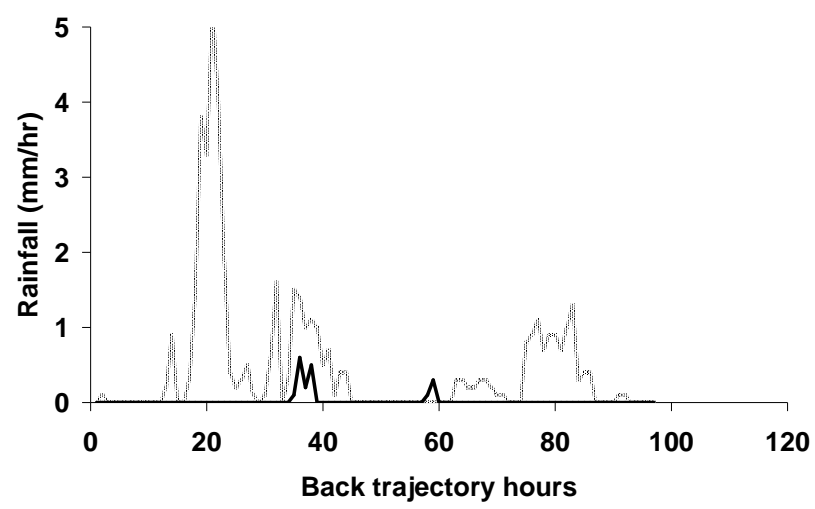

warm sector air rainfall - cool sector air rainfall

Fig. 4. NOAA HYSPLIT rainfall history for the back trajectories indicated in Fig. 3.

expect aggregates of ice crystals to produce multiple IN particles upon evaporation. Figure 5 (and the discussion below) indicates that IN to ice particle concentration ratio ranged from about 0.2 to 10 through most of the first part of the pass from 05:22 to about 05:38 (although most of this time the ratio was well above 1), during the first part of segment "a" in Fig.1. Satellite measured ice water paths were also higher during this segment than the rest of the leg (Fig. 1) and the size distribution revealed a peak in particle sizes at about 650 microns (Fig. 6, blue line). This region had CFDC chamber temperatures slightly colder than ambient at the start of the segment (Fig. 5, bottom). During the next part of the leg (the first part of segment "b" in Fig. 1), between 05:42 and 05:54, ice concentrations were in generally closer agreement with IN concentrations (with ratios of IN to ice concentration ranging from 0.2 to 1.4 ), the size distributions peaked at about 450 microns (Fig. 6 red line), and the chamber temperatures were within about $2{ }^{\circ} \mathrm{C}$ of ambient.

Ice images included rosettes, columns and possibly combinations of side planes, and columns or polycrystalline forms of ice. Aggregates were observed in some places and are discussed below. The habits of the ice particles were often obscured in the 2DC imagery by irregular growth on the edges of the particles but the ice particles did not exhibit rounded edges that might indicate heavy riming (which is consistent with the lack of supercooled liquid water). These types of ice crystals are consistent with growth occurring at temperatures near these sampling temperatures. The observed differences between the IN concentrations and the 2DC concentrations were qualitatively in line with expected IN behavior with changes in temperature and are evident in the beginning and end of the pass (Fig. 5, bottom). When the CFDC chamber was significantly colder than ambient, more IN were measured than ice particles and when the CFDC chamber was warmer than ambient fewer IN than ice particles were observed. It is also evident that the results are not symmetrical
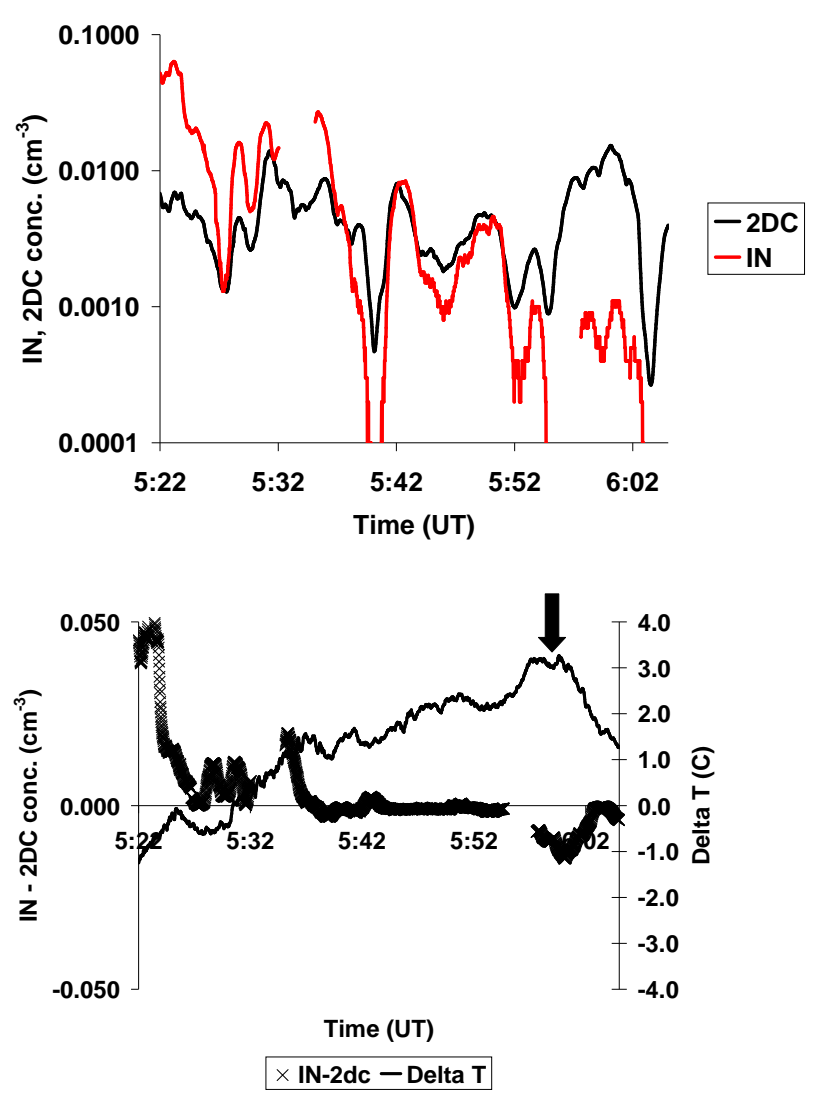

Fig. 5. (Top) Concentrations of ice particles measured by the 2DC and the simultaneous IN concentrations in the particle residuals between 05:22 and 06:05 UTC, which corresponds to the long black track segment in Fig. $1(1 \mathrm{~Hz}$ values smoothed by $60 \mathrm{~s}$ running mean). (Bottom) The difference between the IN concentrations and the 2DC concentrations and the corresponding temperature difference between the CFDC chamber and the ambient temperature ( $1 \mathrm{~Hz}$ values). This pass was made at an altitude of $8.5 \mathrm{~km}$. The chamber temperature at $05: 42$ was $-25^{\circ} \mathrm{C}$. The approximate location of the warm front is given by the arrow.

with respect to temperature (e.g. a positive temperature difference does not carry the same impact as a negative temperature anomaly). In DeMott et al. (2010) three degrees temperature change equates to at most a change in IN concentration of about a factor of 2 for the same aerosol loading. Thus, temperature differences alone cannot explain the results in Fig. 5. In the region where there is the largest discrepancy between the 2DC and the CFDC (05:22 to about 05:40 in Fig. 5 bottom), we believe that this effect is due to a combination of colder temperatures in the CFDC and aggregation of ice particles as discussed below.

A vertical profile through the main part of the warm sector cloud was made in the location described in Fig. 1 (lower left hand black segment). The results from the profile are presented in Fig. 7. IN concentrations were measured at CFDC chamber temperatures between -30 and $-33^{\circ} \mathrm{C}$, 


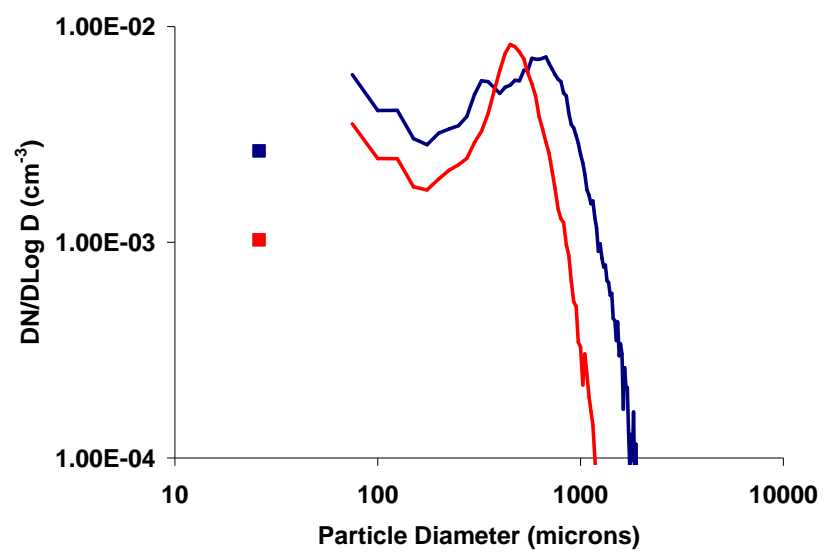

Fig. 6. Cloud Particle size distributions from the 2DC (lines) and the CDP (points) for the period 05:22 to 05:32 UTC (blue, during flight segment "a" in Fig. 1), 05:42 to 05:52 UTC (red, during flight segment "b" in Fig. 1). The CDP registered too few counts to produce a continuous size distribution, so the total concentration from the instrument is included at the midpoint of the sampling range.

representing temperatures just above the top of the profile. IN concentrations were higher than observed 2DC concentrations from the top of the profile to near the freezing level, representing a temperature range of -22 to $0{ }^{\circ} \mathrm{C}$, likely reflecting a combination of colder temperatures in the CFDC and the presence of large aggregates, as revealed in 2DC images, which would be expected to contain multiple IN (i.e. one for each crystal in the aggregate). These results are suggestive of heterogeneous freezing occurring at colder temperatures in the mid or upper cloud regions (in this example between -24 to $-33^{\circ} \mathrm{C}$ ) supplying aggregates to warmer temperatures. Aggregate ice particles of 450 to 650 microns (Fig. 6) which were sampled at $8.5 \mathrm{~km}$ altitude, should have sufficient fall speed (of order $0.5 \mathrm{~m} \mathrm{~s}^{-1}$ ) to reach the lower levels of the cloud displayed in Fig. 7 in reasonable times (e.g. ice particles should descend from $8.5 \mathrm{~km}$ to $6.5 \mathrm{~km}$ in slightly over $1 \mathrm{~h}$ ).

The correlation between IN and ice particles is further examined in Fig. 8. In region b, before the area of the warm front was encountered (Fig. 8, black symbols), the nearly one-to-one correspondence between the IN and 2DC concentrations, as discussed above, is clearly evident. During this time single ice crystals predominated in the 2DC imagery (Fig. 8). During the earlier period (region a), where larger particles predominated, aggregation was evident in the 2DC images and during this time there were more IN than ice particles (Fig. 8 red symbols) similar to that observed in the vertical profile (Fig. 8, blue symbols). The observed agreement between IN and ice particles in region $\mathrm{b}$ and the observations of more IN than ice particles in regions where aggregation was evident supports the hypothesis that heterogeneous freezing was responsible for the observed ice concentrations in this part of the warm sector cloud. Other explanations for the correspondence between IN and ice particles might be

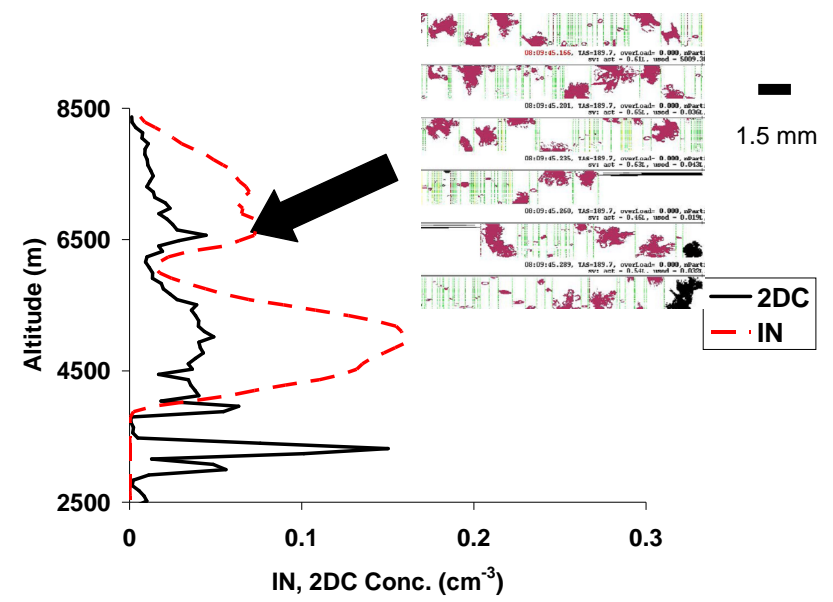

Fig. 7. Vertical profile of IN and $2 D C$ concentrations in the warm sector cloud just above the front with the CFDC sampling from the CVI inlet. The location of the profile is in the lower left hand dark track in Fig. 1. The freezing level was at $4.2 \mathrm{~km}$ altitude. The CFDC was operated at a temperature between -30 and $-33^{\circ} \mathrm{C}$. 2DC ice particle images from the 2DC taken at $6.5 \mathrm{~km}$ altitude are also shown.

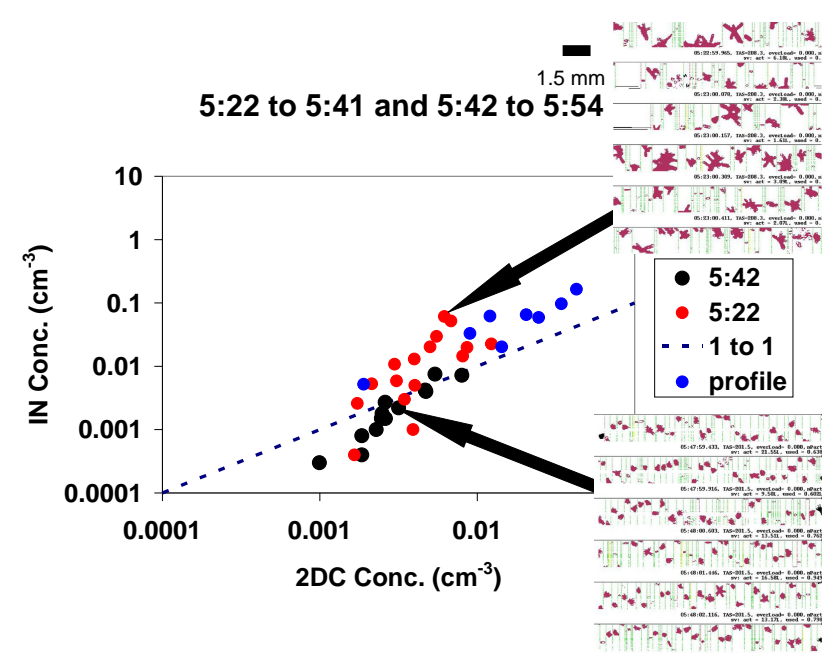

Fig. 8. Ice Nuclei and $2 \mathrm{DC}$ concentrations for the periods $05: 22$ to $05: 41$ (data from 05:33-05:35 are not available, red symbols), 05:42 to 05:54 (black symbols) and during the upper part (temperatures between -22 and $-3{ }^{\circ} \mathrm{C}$ ) of the vertical profile in Fig. 7 (blue symbols). Data are 60 averages. 2DC images corresponding to the selected points (arrows) are included.

possible, but this seems to be the most likely explanation for these results.

\section{$5 \mathrm{rBC}$ and other aerosols in the warm-sector clouds}

Total particle concentrations and $\mathrm{rBC}$ from the SP2 were measured in the CVI sample stream simultaneously with the 


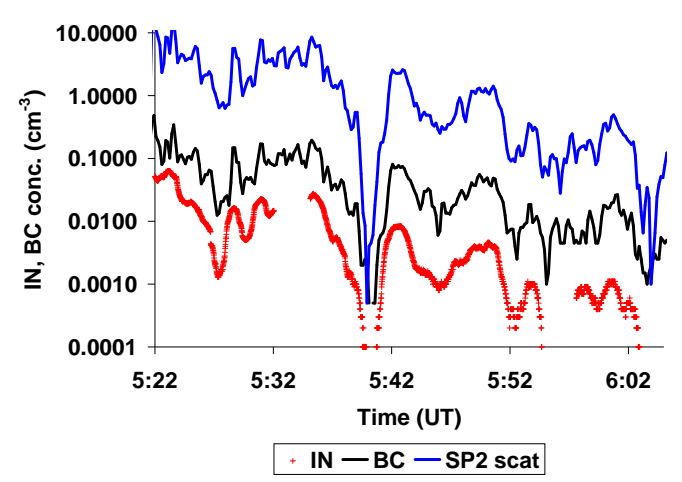

$5: 22$ to $5: 41$ and $5: 42$ to $5: 54$

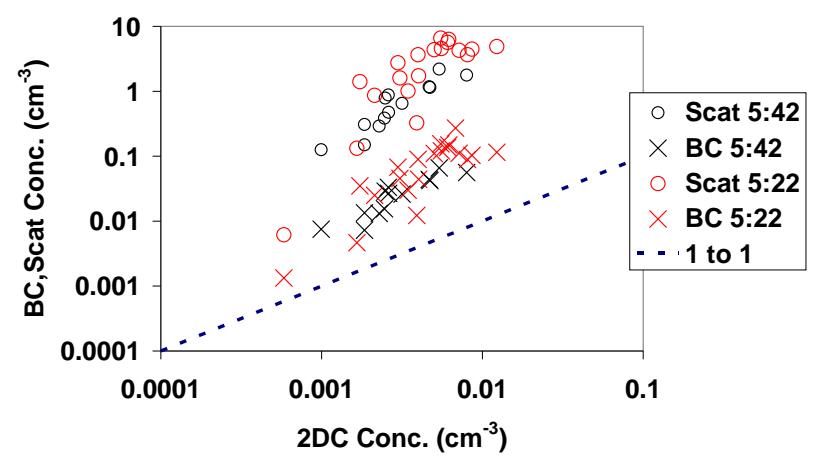

Fig. 9. Number concentrations of total SP2 scattering, rBC and IN concentrations in CVI residuals versus time (top). $60 \mathrm{~s}$ average values versus $2 \mathrm{DC}$ concentration (bottom) for the indicated time periods.

IN. The results from the horizontal pass are given in Fig. 9. The SP2 data in this pass showed a gradient of concentration in the SP2 data from the west to the east, with higher concentrations in the west (Figs. 1 and 9 - top). Comparing Figs. 5 and 8 with Fig. 9 indicates that $\mathrm{rBC}$ concentrations in ice particle residuals were substantially higher than either the IN or the 2DC ice concentrations (about a factor 2 to 40 times higher than the 2DC concentrations) and the total number of particles seen by the SP2 was even greater (a factor of 80 to over 1000 times higher than the 2DC). This suggests that each ice particle contained multiple aerosol particles, including rBC, compared to the number of IN in the particles. This observation appears qualitatively consistent with effects due to non-nucleation scavenging as discussed below. As was the case with IN, higher numbers of $\mathrm{rBC}$ and total particles were found per ice particle in region a, where aggregation was occurring. This was also evident in SP2 data during the vertical profile which is shown in Fig. 10 and discussed below.

An out of cloud sample (using the modular inlet instead of the CVI) in the warm sector air for the SP2 was available between 06:21 and 06:25 in the extreme southeast leg of the sampling area at the same altitude as the cloud leg in
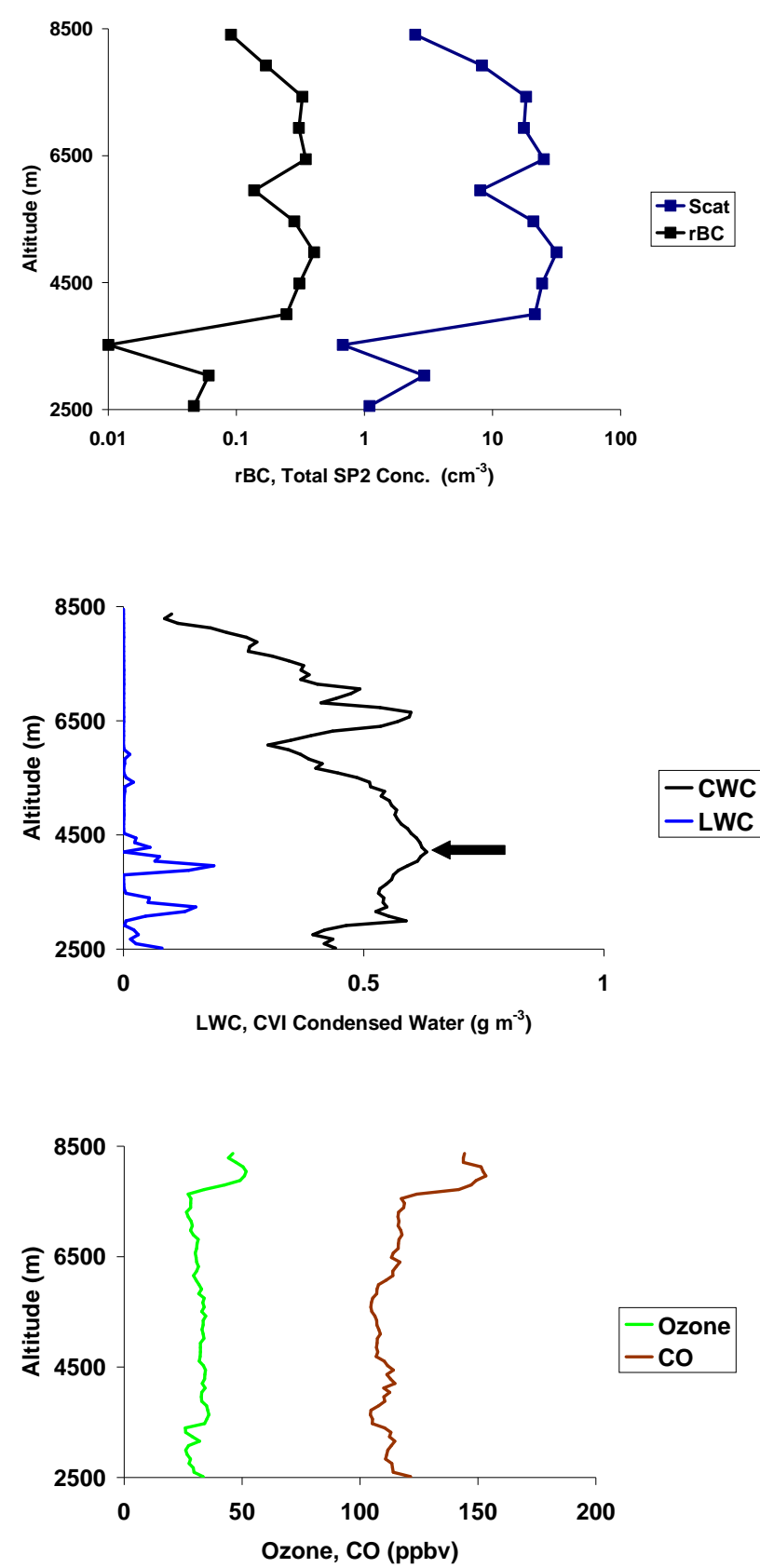

Fig. 10. Profile of warm sector cloud just above the front as in Fig. 7, but showing the SP2 total particle (Scat) and rBC number concentration (top, based on $60 \mathrm{~s}$ averaged data taken from the CVI inlet), liquid and total water concentration (middle) and the $\mathrm{CO}$ and Ozone mixing ratios (bottom). The freezing level was at $4.2 \mathrm{~km}$ altitude (arrow).

Fig. 5 ( $8.5 \mathrm{~km})$. Concentrations in the clear air between 06:21 and $06: 25$ averaged $3.3 \mathrm{~cm}^{-3}$ and $1.4 \mathrm{~cm}^{-3}$ for the SP2 total scattering and $\mathrm{rBC}$ concentrations, respectively. The nearest in cloud sample from the CVI residuals in the eastern portion of the warm sector cloud around 05:56-05:57 indicates a 
concentration of approximately $0.1 \mathrm{~cm}^{-3}$ and $0.01 \mathrm{~cm}^{-3}$ for the SP2 total scattering and $\mathrm{rBC}$ concentrations, respectively (Fig. 9). These data suggest that the in cloud CVI residuals in the eastern part of the leg upon evaporation produced only a small fraction of the aerosol that was present in the clear air.

Only a brief sample of clear air in the warm sector in the western sampling regions is available between $02: 23$ and 02:25, just above the cloud between 9.9 and $8.5 \mathrm{~km}$ altitude, which exhibited SP2 total scattering and $\mathrm{rBC}$ concentrations of $2.5 \mathrm{~cm}^{-3}$ and $0.84 \mathrm{~cm}^{-3}$, respectively. In cloud on the western part of the sampling leg, SP 2 concentrations from the CVI residuals ranged from about 0.1 to $10 \mathrm{~cm}^{-3}$ and 0.01 to $0.2 \mathrm{~cm}^{-3}$ for the total scattering and $\mathrm{rBC}$ concentrations, respectively (Fig. 9). Thus, SP2 concentrations from the CVI cloud particle residuals in the western part of the sampling area appear to be similar to out of cloud values for the total scattering signal and slightly less than out of cloud values for the $\mathrm{rBC}$ signal. It appears that the ice particles in the western sector of the sampling leg contained a higher percentage of out of cloud values of rBC and total particles than did those in the eastern section. According to the size distributions and the particle imagery (e.g. Figs. 6 and 8), ice particles in the western sector were significantly larger than those in the eastern section, which would favor more non-nucleation scavenging, through longer growth times and more surface area available for scavenging.

Since these results suggest the possibility of varying amounts of $\mathrm{rBC}$ compared to total particles measured by the SP2 in different parts of the cloud, we examine the ratio of the $\mathrm{rBC}$ concentration to the total SP2 concentration as a function of condensed water content in Fig. 11 (top). For comparison, the ratio of IN to total particles is also given in Fig. 11 (bottom). rBC particles constituted from a few percent to over ten percent of the total SP2 particles and this ratio appears to increase with decreasing condensed water content (Fig. 11 top). In contrast, IN concentrations generally constitute less than $1 \%$ of the total particles measured by the SP2 and show a constant or slight increase in this ratio with increasing condensed water content (Fig. 11 bottom). This suggests a different scavenging history for rBC compared to other particles (IN or total particles) in the storm (e.g. as might be a result of different sizes for the rBC compared to the other particles).

The vertical profile of $\mathrm{rBC}$, total SP2 particles, liquid water, condensed water, ozone, and $\mathrm{CO}$ corresponding to the profile in Fig. 7 is given in Fig. 10. Concentrations of SP2 $\mathrm{rBC}$ and total particles, especially between $7.5 \mathrm{~km}$ altitude and the freezing level, were higher by a factor of more than 2, compared to similar concentrations in the upper regions of the cloud (Fig. 9). The higher concentrations in the residuals in this lower portion of the storm may be the result of two factors. First, CVI SP2 total concentrations in the residuals during this profile were greater than clear air values (described above) at higher altitudes, which suggests the possi-
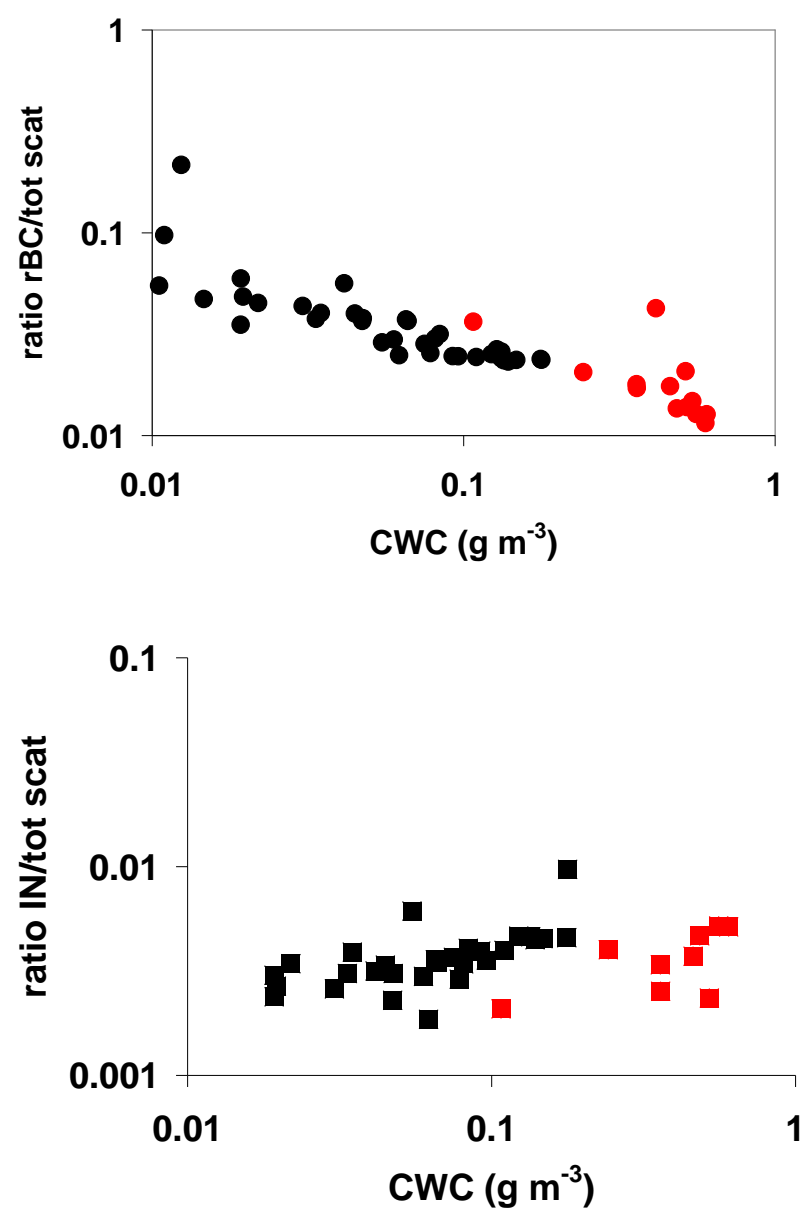

Fig. 11. The ratio of $\mathrm{rBC}$ to total particle concentration from the SP2 instrument for the period 05:22 to 05:57 and during the vertical profile in Fig. 10 (in red) versus condensed water content (top). The corresponding ratio of IN to total particle concentration versus condensed water content for the period 05:22 to 05:54 (bottom, data not available 05:33-05:35) and for the portion of the vertical profile colder than freezing in Fig. 10 (in red). Data are $60 \mathrm{~s}$ averages.

bility of more aerosols present at lower levels of warm sector air in this storm. Second, the condensed water content between $7.5 \mathrm{~km}$ altitude and the freezing level (Fig. 10 middle) was much higher than that found in the upper portions of the cloud (see Fig. 11). Thus additional condensed water (and ice particle surface area) could explain much of the difference between residual SP2 concentrations found in Figs. 9 and 10, together with the possibility of somewhat higher aerosol levels in the mid levels of warm sector cloud.

In portions of the cloud that were warmer than freezing much lower levels of $\mathrm{rBC}$ and total particles were found, even though the water content of the warm cloud was similar to the ice cloud just above it (Fig. 10, top and middle). Examination of $\mathrm{CO}$ and ozone in the lower regions of the clouds (Fig. 10, bottom) indicates generally similar airmass trace gas characteristics in the lower part of the warm sector cloud, so the 
observed differences in $\mathrm{rBC}$ could be due to differences in scavenging history in the parts of the warm sector cloud that contained ice compared to the parts that were liquid. However, this portion of the cloud also contained a substantial amount of condensed water as drizzle and rain, residuals of which may be collected less efficiently by the CVI.

Precise non-nucleation scavenging calculations of aerosol particles by ice crystals are not possible due to uncertainties in the thermodynamic history and residence time of the sampled crystals, their irregular shapes, and the size distribution of interstitial aerosol. Nevertheless, some magnitude of nonnucleation scavenging was estimated based on results shown in Fig. 1 and Table 1 of Miller and Wang (1989). Their calculations at $600 \mathrm{mb}, 253 \mathrm{~K}$, and $95 \%$ relative humidity with respect to ice for columnar crystals scavenging aerosol particles include Brownian diffusion, gravitational, inertial, thermophoretic and diffusiophoretic processes. Scavenging rates are dependent on a number of factors and are largest for particles smaller than $0.1 \mu \mathrm{m}$, where Brownian diffusion dominates. However, scavenging still may be significant for particles larger than $0.1 \mu \mathrm{m}$ due to the other modeled processes. Ambient size distributions from the UHSAS and condensation nuclei $(\mathrm{CN})$ data from this case were used to estimate the number of aerosol particles that may have been scavenged by large ice crystals, which are expected to have dominated both the scavenging of particles within the cloud and residual particle generation due to breakup within the CVI. Based on these these approximations, scavenging rates could be hundreds or more per crystal per hour in the $\mathrm{CN}$ size range, and tens of particles per crystal/hour in the UHSAS size range.

Lower relative humidities and electrical effects, if present, could dramatically enhance scavenging rates (Miller and Wang, 1989), as might turbulent effects (Martin et al., 1980). Additionally, the sometimes irregular, high-surface-area ice crystals measured in this storm may have higher scavenging rates than the simple columns modeled by Miller and Wang (1989). Thus, non-nucleation scavenging seems to be a possible explanation for the observed higher numbers of rBC and total particles in the CVI residuals than expected from nucleation scavenging alone. This is in accord with the suggestions made by Baumgardner et al. (2008), and is important to keep in mind when interpreting CVI results. Other sources for enhanced particle concentrations are also possible, as discussed in Sect. 2. Clearly, further investigation of the sources of non-IN particles in the CVI residuals is needed in future work.

\section{Aerosol and IN compositions in the CVI residual particles}

CVI residual particles were collected and examined by Scanning and Transmission Electron microscopy (SEM and TEM, respectively) and their composition determined using Energy-dispersive X-ray spectroscopy (EDS). Two cat- egories of samples were examined. The first category was the residual particles from the CVI which were available on filters or TEM grids (CVI category) and the second was samples taken from residuals that had formed ice in the CFDC and were deposited (and subsequently evaporated) on TEM grids (CFDC category). Both SEM and TEM analysis is available for the CVI category, but only TEM analysis was used for the CFDC TEM grids. The TEM samples were collected by impaction on grids with carbon support films and the effective smallest size that was routinely analyzed was approximately $50 \mathrm{~nm}$ (features as small as $20 \mathrm{~nm}$ can be resolved under the analytical conditions). The SEM analysis was both by manual techniques (for which $50 \mathrm{~nm}$ can be observed but the collection efficiency drops off rapidly below $100 \mathrm{~nm}$ ) and by automated techniques with a lower size limit of approximately $200 \mathrm{~nm}$. The automated SEM provides analysis of thousands of particles per flight. TEM analysis is able to detect and study the presence and nature of inclusions in individual aerosol particles. While the SEM analysis cannot separately analyze the inclusions, they contribute to the composition of the particle by SEM EDS analysis.

The primary purpose of this effort is to characterize the subset of the CVI residual particles that act as IN. A secondary purpose was to determine if there was a noteworthy contribution from $\mathrm{rBC}$ particles to IN. Third, EDS was used to determine what contribution to the CVI residual particles might be due to ablation of the CVI inlet by ice particles, such as suggested by the studies by Murphy et al. (2004) and Kojima et al. (2004). We first discuss the results of the EDS analysis for inlet materials and the likelihood of artifacts from the inlet.

The G-V CVI inlet was made entirely of commercially pure, grade 2 titanium in order to more easily identify inlet material. To test for possible secondary particles generated from ablation of the inlet, 7168 particles sampled downstream of the CVI in this case study were analyzed for titanium by SEM and X-ray analysis. The 7168 particles included particles from both the warm and cold sector regions of the storm. Particles with high enough titanium levels to potentially be from the inlet were $4.1 \%$ of the total number. However, titanium particles exhibited a strong size dependence relative to other CVI residuals as shown in Fig. 12. For supermicron particles, 8 to $31 \%$ were titanium, for micron sized particles, $4.4 \%$ were titanium, while for the smallest particles detected by SEM ( $\sim 0.1$ to $0.3 \mu \mathrm{m})$, only $1.5 \%$ were titanium. Due to the high density of titanium, percentages for aerodynamic or mass equivalent diameters would be even smaller. For the total population of analyzed CVI particles with an nominal lower detection limit of $200 \mathrm{~nm}$ (although some particles as small as $100 \mathrm{~nm}$ were analyzed), the median geometric diameter was 0.62 microns, while titanium particles had a median diameter of 1.2 microns. This is in contrast to the results for Murphy et al. (2004) who showed no substantial size-dependence for inlet metals vs. other detected particles. 

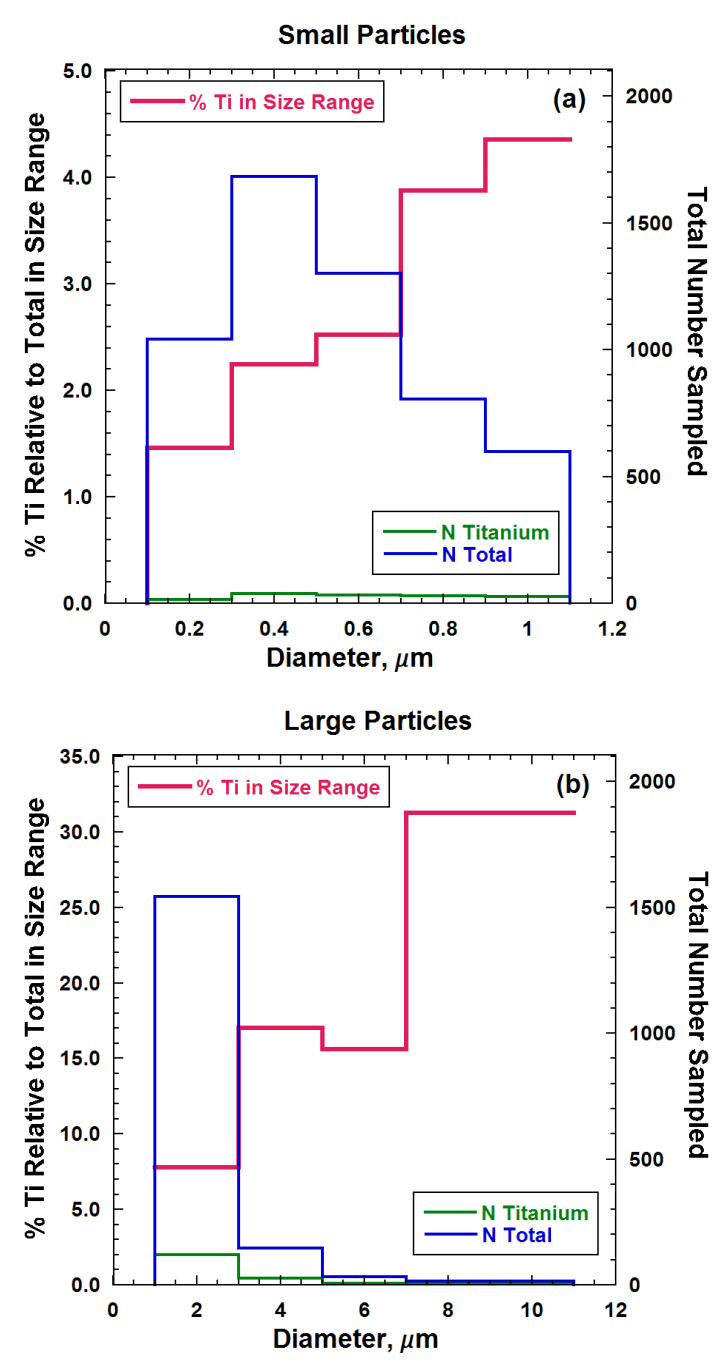

Fig. 12. The percent (red) of titanium particles relative to the total number of CVI residual samples in different size ranges. Also shown is the total number of particles (blue) and those containing titanium (green.) Smaller particles are shown in (a) and larger ones in (b). Diameter is the average of physical length and width as measured via SEM.

We do not believe titanium from the inlet affected the IN measurements, since on this day the particle types collected downstream of the CFDC that nucleated ice did not contain titanium, except for one organic particle with a titanium ovoid inclusion and therefore is not likely an ablation artifact. Additionally, in many years of collecting IN samples from the CFDC in the field, only one other particle containing titanium has been identified, and that appeared to be a spherical aggregate of $\mathrm{TiO}_{2}$ from industrial processes (DeMott et al., 2004). Thus titanium does not appear to be a very efficient ice nucleus.

Whether or not titanium metal particles will incandesce in the SP-2 is unknown, as this composition has not been tested in the laboratory. Due to this uncertainty, the CVI/SP2 data should be considered an upper limit for $\mathrm{rBC}$ in the CVI samples. We plan future tests with titanium in the SP2 to better understand its response to this metal. While we cannot state with certainty that the measured $\mathrm{rBC}$ concentrations were not affected by titanium from the inlet, we do not believe they were a large fraction of the concentration measured for the following reasons. First, as we note in Sect. 5, SP2 samples in the warm sector ambient air (out of cloud in relatively dust-free air) through a different, non titanium, inlet revealed a greater percentage of $\mathrm{rBC}$ as a fraction of total scattering particles than did the samples that were taken in cloud through the CVI in the warm sector air. This is not what you would expect if the SP2 signal for $\mathrm{rBC}$ in the CVI samples was due to Ti from the inlet. Second, Fig. 11 (top) suggests that the fraction of SP2 particles that were rBC increased with decreasing condensed water content, which also seems inconsistent with the inlet as a source of the rBC signal in the SP2. Finally, a fraction of these Ti-bearing particles may have been present naturally in the residuals. EDS analysis of samples taken in the cool sector air outside of cloud and also through a non-titanium inlet indicated that the percent of titanium particles was about $0.25 \%$ of the total number in that region of the air near the storm. Although this was a different airmass than the warm sector, it suggests the presence of some titanium in the atmospheric aerosol (probably associated with silicate dust particles with which titanium would be expected).

A total of 4108 CVI particles and 80 CFDC particles from the warm sector of the storm have been examined to-date using SEM (for the CVI samples) and TEM (for the CFDC particles). Several hundred additional CVI particles were examined by TEM, but heavy loading of the grid made it difficult to distinguish separate particles in some cases. Both categories contained large fractions of particles that appear to be amorphous organic material by internal structure and electron contrast as observed by TEM. Most of these particles have many small $(20-50 \mathrm{~nm})$ inclusions. An example image of one typical particle is provided in Fig. 13. EDS of similar particles that did not contain inclusions revealed only carbon and oxygen (hydrogen cannot be done by EDS and nitrogen is best done by other methods), indicating the organic nature of the material. Approximately half of the CFDC particles were organic particles with inclusions. These particles contained potassium and various combinations of sodium, magnesium, calcium, potassium, sulfur and chlorine which is probably a reflection of the combined composition of the inclusions. This set of elements is also found in the majority of the CVI particles analyzed by SEM (but in the SEM the presence of inclusions cannot be observed except at the surface). Small silica particles may be also present as inclusions in a minority of the organic particles in the CVI samples. Potassium is often associated with biomass burning (Andreae, 1983; Andreae and Merlet, 2001) and 70\% of the CVI particles in the SEM results have detectable potassium. 


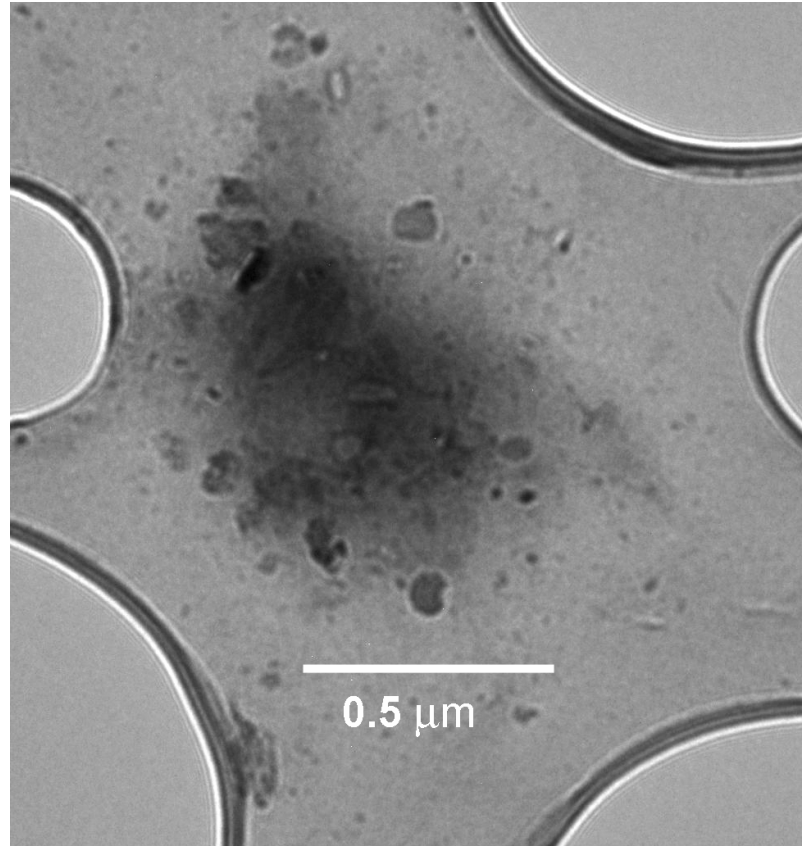

Fig. 13. TEM image of one of the residual particles from the CVI, showing the presence of inclusions in amorphous organic material. See text for more explanation.

This is a very high percentage that suggests a possible dominant biomass burning origin for the aerosol, perhaps mixed with aerosol from other sources. Also present are sulfate particles, non-rBC carbonaceous particles without inclusions (probably either biogenic or organic), and a few rBC particles. A major difference between the CVI and CFDC samples is that sea salt is present in almost half of the particles larger than $200 \mathrm{~nm}$ observed by automated SEM in the CVI samples (and also observed by TEM) but is not observed in the CFDC sample (observed by TEM).

These organic particles with inclusions were the most abundant aerosol particle type and were the likely source of the total particle number concentration seen by the SP2, which was typically an order of magnitude or higher in concentration than the rBC concentration (Fig. 11). Only a few distinct aggregates of carbon spherules (i.e., soot) were found as separate particles distinct from the inclusion-bearing organic particles. However, nanoscale rBC inclusions (20$30 \mathrm{~nm}$ or smaller) may be present in the organic particles and appear to be the most likely explanation for the small component of aerosol that registered as $\mathrm{rBC}$ on the SP2.

Ammonium sulfate was present both as separate particles and as inclusions in larger organic particles. Of the $4108 \mathrm{CVI}$ particles that were analyzed, only 28 of them were primarily silica and 42 were aluminosilicates (such as clay) with a median diameter of $0.9 \mu \mathrm{m}$ for the 70 particles. (77\% of the analyzed SEM particles are between 200-1000 nm diameter). Aluminosilicates, a common class of IN, were not observed in the $80 \mathrm{CFDC}$ samples (i.e. none contained $\mathrm{Al}$ ). Interference problems with $\mathrm{Si}$ for the CFDC grid made it difficult to compare this element for CVI and CFDC particles.

A comparison between the TEM EDS analysis of the CVI and CFDC samples reveals that the organic-rich particles in CFDC samples were higher in calcium ( $75 \%$ of this category contained $\mathrm{Ca}$ ), with a median size of $0.7 \mu \mathrm{m}$ for the CFDC particles. This suggests the possible involvement of calcite and gypsum which have been observed to have ice nucleating ability in at least one study (Roberts and Hallett, 1968).

While some studies have inferred that organic coatings are detrimental to ice nucleation, Koehler et al. (2010) have shown that this is not the case for coatings in the mixed phase cloud regime warmer than $-36^{\circ} \mathrm{C}$ for the case of dust particles coated with secondary organic aerosol created by the reaction of $\alpha$-pinene with ozone.

\section{Discussion and summary}

Few concurrent measurements of ice particle concentrations and measurements of IN from within ice crystals are available. Understanding and predicting the concentration of ice in clouds has been remarkably difficult (e.g. Cantrell and Heymsfield, 2005), so these results suggest that predicting the levels of IN present in regions where heterogeneous freezing is active should be helpful in predicting ice concentrations in storms.

The evidence presented here suggests that large ice crystals, such as we observed in the midlevels of an extratropical storm, release multiple aerosol particles upon evaporation in the CVI. However, the subset of these aerosols that are IN correspond with the number of single ice crystals measured in the cloud at storm midlevels when the CFDC was processing at similar temperatures and there are more IN than ice particles when the ice particles are aggregates of crystals. The most plausible explanation for these results is that IN survive the passage through the CVI intact and that heterogeneous freezing had occurred on these IN. Our observations suggest a conceptual model for ice formation in these warm sector clouds where heterogeneous freezing supplies large numbers of ice crystals to the mid or upper regions of the storm and these particles continue to grow and aggregate as they descend to warmer temperatures. Satellite observations of this storm suggest that the highest tops of the clouds were cold enough that homogeneous freezing might also be important in other parts of the storm, however ice multiplication via Hallett-Mossop rime splintering appears unlikely in this case due to the near absence of liquid water (and graupel, not shown) in temperatures where rime splintering occurs (Fig. 10). These conclusions could be further examined through numerical simulations.

It would certainly be helpful if the shattering/breakup of particles in the CVI or on the tips of cloud probes were better characterized. This is an area of active research. We have 
begun to model these processes within the NCAR CVI inlet using computational fluid dynamical modeling in conjunction with aerodynamic breakup theory. In future work, these results will be compared with observations or residual number in this and other field projects. We also wish to caution that shattering results using this particular CVI inlet are not necessarily transferable to other CVI inlets with different geometries. In particular, the NCAR CVI inlet is routinely used for measurements of total condensed water content (liquid plus ice). Since we wish to retain large ice that can provide a substantial fraction of total condensed water, this CVI inlet does not employ a "waste flow" at the back of the inlet to remove large crystals that may survive intact. Such a geometry has been employed and discussed by Ström et al. (1999), and may reduce the shattering effect.

$\mathrm{rBC}$ particles were somewhat more numerous than IN and particles that are neither IN or rBC predominate in cloud particle residuals, conclusions that, at least qualitatively, are supported by the electron microscope analysis. The observation that the IN are a small subset of the total aerosols released when the ice particles evaporates argues against nucleation scavenging as the source of the particles in the residuals (i.e. in agreement with Baumgardner et al., 2008), so another explanation including non-nucleation scavenging seems likely. For example, Miller and Wang (1989), based on a review of field observations, suggest that falling ice crystals may remove particles up to fifty times more efficiently than the equivalent liquid water content of falling raindrops. Regions where larger ice particles predominated appear to contain more $\mathrm{rBC}$ and total particles in the ice phase, compared to regions with smaller ice particles, which is also consistent with such a scavenging mechanism. The observation that the fraction of rBC compared to total particles in the residuals increases with decreasing condensed water content, while the fraction of IN compared to total particles does not (Fig. 11), suggests that the scavenging for $\mathrm{rBC}$ is different than for IN. This would be expected if the IN in general are from a different aerosol type (e.g. in terms of size and composition) than the $\mathrm{rBC}$ for this case.

Twohy et al. (2010) found ice concentrations in orographic clouds over the western United States were correlated with upstream concentrations of biomass burning aerosol particles. Our measurements and observations suggest that biomass burning derived organic and refractory black carbon from East Asia are incorporated into the ice phase of Pacific extratropical storms. While a small proportion of these particles acted as IN in high enough concentrations to explain the observed ice concentrations in the storm through heterogeneous nucleation, the primary route for the $\mathrm{rBC}$ (and other particle) incorporation into the ice phase appears to be through non nucleation scavenging. Based upon the chemical analyses on the IN that has been done to-date, particles that served as IN were found to be slightly enhanced in calcium and less influenced by sea salt, but were otherwise similar to other residual particles that were found in the sample.
Chemical and morphological analysis of the residuals and IN particles collected during this storm and from other PACDEX cases continues and should provide more details on the properties of this important class of aerosol.

Acknowledgements. The National Center for Atmospheric Research is supported by the National Science Foundation. This work was also supported by NSF Grants ATM-0611936 (DeMott), ATM-0612605 (Baumgardner), ATM-0612605 (Twohy), and ATM-076671 (Anderson). Additional support was provided by NASA grant NNX08AH57G (Twohy). The assistance with the 2DC processing software by A. Bansemer and assistance with the interpretation of the SP2 data from R. Subramanian is appreciated. Comments on the manuscript by J. Jensen and L. Emmons are also appreciated. The authors gratefully acknowledge the NOAA Air Resources Laboratory (ARL) for the provision of the HYSPLIT transport and dispersion model and used in this publication. P. DeMott gratefully acknowledges the TEM analysis support of R. J. Lee Inc. (Monroeville, PA). Assistance by X. Hua and S. Santra with SEM and TEM analysis is also gratefully acknowledged.

Edited by: D. J. Cziczo

\section{References}

Anderson, T. L. and Twohy, C. H.: Collection and exclusion of large cloud elements with a counterflow virtual impactor, Twelfth Annual Conference, Oak Brook, Illinois, American Association for Aerosol Research, 36, 1993.

Andreae, M. O.: Soot carbon and excess fine potassium: Longrange transport of combustion-derived aerosols, Science, 220, 1148-1151, 1983.

Andreae, M. O. and Merlet, P.: Emission of trace gases and aerosols from biomass burning, Global Biogeochem. Cy., 15, 955-966, 2001.

Baumgardner, D., Subramanian, R., Twohy, C., Stith, J., and Kok, G: Scavenging of black carbon by ice crystals over the northern Pacific, Geophys. Res. Lett., 35, L22815, doi:10.1029/2008GL035764, 2008.

Cantrell, W. and Heymsfield, A. J.: Production of ice in tropospheric clouds. A review, B. Am. Meteorl. Soc., 86, 795-807, doi:10.1175/BAMS-86-6-795, 2005.

Chen, J.-P. and Crutzen, P. J.: Solute effects on the evaporation of ice particles, J. Geophys. Res., 99(D9), 18847-18859, doi:10.1029/94JD01346, 1994.

Cozic, J., Mertes, S., Verheggen, B., Cziczo, D. J., Gallavardin, S. J., Walter, S., Baltensperger, U., and Weingartner, E.: Black carbon enrichment in atmospheric ice particle residuals observed in lower tropospheric mixed phase clouds, J. Geophys. Res., 113, D15209, doi:10.1029/2007JD009266, 2008.

DeMott, P. J., Cziczo, D., Jimenez, J., Brooks, S., Richardson, M., Dunlea, E., Koehler, K., Prenni, A., Kreidenweis, S., Borys, R., and Murphy, D.: Physical and chemical impacts on the ice nucleating properties of atmospheric particles, 14th International Conf. on Clouds and Precipitation, IAMAS-ICCP 2004, Bologna, Italy (on CD-ROM), 2004.

DeMott, P. J., Prenni, A. J, Liu, X., Kreidenweis, S. M., Petters, M. D., Twohy, C. H., Richardson, M. S., Eidhammer, T., and Rogers, 
D. C.: Predicting global atmospheric ice nuclei distributions and their impacts on climate, P. Natl. Acad. Sci. USA, 107, 1121711222, 2010.

Draxler, R. R. and Rolph, G. D.: HYSPLIT (HYbrid Single-Particle Lagrangian Integrated Trajectory) Model access via NOAA ARL READY Website (http://ready.arl.noaa.gov/HYSPLIT. php), NOAA Air Resources Laboratory, Silver Spring, MD, 2010.

Eidhammer, T., DeMott, P. J., Prenni, A. J., Petters, M. D., Twohy C. H., Rogers D. C., Stith, J., Heymsfield, A., Wang, Z., Pratt, K. A., Prather, K. A., Murphy, S. M, Seinfeld, J. H., Subramanian, R., and Dreidenweis, M.: Ice Initiation by Aerosol Particles: Measured and Predicted Ice Nuclei Concentrations versus Measured Ice Crystal Concentrations in an Orographic Wave Cloud, J. Atmos. Sci., 67, 2417-2436, doi:10.1175/2010JAS3266.1, 2010.

Field, P. R., Heymsfield, A. J., and Bansemer, A.: Shattering and Particle Interarrival Times Measured by Optical Array Probes in Ice Clouds, J. Atmos. Oceanic Tech., 23, 1357-1371, 2006.

Glantz, P., Noone, K. J., and Osborne, S. R.: Comparisons of airborne CVI and FSSP measurements of cloud droplet number concentrations in marine stratocumulus clouds, J. Atmos. Ocean. Tech., 20, 133-142, 2003.

Hadley, O. L., Ramanathan, V., Carmichael, G. R., Tang, Y., Corrigan, C. E., Roberts, G. C., and Mauger, G. S.: TransPacific transport of black carbon and fine aerosols $(D<$ $2.5 \mu \mathrm{m}$ ) into North America, J. Geophys. Res., 112, D05309, doi:10.1029/2006JD007632, 2007.

Jacobson, M.: Effects of externally-through-internally-mixed soot inclusions within clouds and precipitation on global climate, J. Phys. Chem. A., 110, 6860-6873, 2006.

Jensen, E. J., Lawson, P., Baker, B., Pilson, B., Mo, Q., Heymsfield, A. J., Bansemer, A., Bui, T. P., McGill, M., Hlavka, D., Heymsfield, G., Platnick, S., Arnold, G. T., and Tanelli, S.: On the importance of small ice crystals in tropical anvil cirrus, Atmos. Chem. Phys., 9, 5519-5537, doi:10.5194/acp-9-5519-2009, 2009.

Kojima, T., Buseck, P. R., Wilson, J. C., Reeves, J. M., and Mahoney, M. J.: Aerosol particles from tropical convective systems: Cloud tops and cirrus anvils, J. Geophys. Res., 109, D12201, doi:10.1029/2003JD004504, 2004.

Koehler, K. A., Kreidenweis, S. M., DeMott, P. J., Petters, M. D., Prenni, A. J., and Möhler, O.: Laboratory investigations of the impact of mineral dust aerosol on cold cloud formation, Atmos. Chem. Phys., 10, 11955-11968, doi:10.5194/acp10-11955-2010, 2010.

Martin, J. J., Wang, P. K., and Pruppacher, H. R.: A theoretical determination of the efficiency with which aerosol particles are collected by simple ice crystal plates, J. Atmos. Sci., 37, 16281638, 1980.
Miller, N. L and Wang, P. K.: Theoretical determination of the efficiency of aerosol particle collection by falling columnar ice crystals, J. Atmos. Sci., 46, 1656-1663, 1989.

Murphy, D. M., Cziczo, D. J., Hudson, P. K., Thomson, D. S., Wilson, J. C., Kojima, T., and Buseck, P. R.: Particle generation and ressuspension in aircrafts inlets when flying in clouds, Aerosol Sci. Technol., 38, 400-408, 2004.

Pilch, M. and Erdman, C. A.: Use of breakup time data and velocity history data to predict the maximum size of stable fragments for acceleration-induced breakup of a liquid drop, Int. J. Multiphas. Flow, 13, 741-757, 1987.

Roberts, P. and Hallett, J.: A laboratory study of the ice nucleating properties of some mineral particulates, Q. J. Roy. Meteorol. Soc., 94, 25-34, 1968.

Schwarzenböck, A. and Heintzenberg, J.: Cut size minimization and cloud element break-up in a ground-based CVI, J. Aerosol Sci., 31, 477-489, 2000.

Seinfeld, J. H., Carmichael, G. R., Arimoto, R., Conant, W. C., Brechtel, F. J., Bates, T. S., Cahill, T. A., Clarke, A. D., Doherty, S. J., Flatau, P. J., Huebert, B. J., Kim, J., Markowicz, K. M., Quinn, P. K., Russell, L. M., Russell, P. B., Shimizu, A., Shinozuka, Y., Song, C. H., Tang, Y. H., Uno, I., Vogelmann, A. M., Weber, R. J., Woo, J. H., and Zhang, X. Y.: ACE-ASIA - Regional climatic and atmospheric chemical effects of Asian dust and pollution, B. Am. Meteorol. Soc., 85, 367-380, 2004.

Stith, J. L., Ramanathan, V., Cooper, W. A., Roberts, G. C., DeMott, P. J., Carmichael, G., Hatch, C. D., Adhikary, B., Twohy, C. H., Rogers, D. C., Baumgardner, D., Prenni, A. J., Campos, T., RuShan Gao, Anderson, J., and Feng, Y.: An overview of aircraft observations from the Pacific Dust Experiment campaign, J. Geophys. Res., 114, D05207, doi:10.1029/2008JD010924, 2009.

Ström, J., Fischer, H., Lelieveld, J., and Schröder, F.: In situ measurements of microphysical properties and trace gases in two cumulonimbus anvils over western Europe, J. Geophys. Res., 104, 12221-12226, 1999.

Tarnogrodzki, A.: Theoretical prediction of the critical Weber number. Int. J. Multiphas. Flow, 19, 329-336, 1993.

Twohy, C. H., Strapp, J. W., and Wendisch, M.: Performance of a counterflow virtual impactor in the NASA Icing Research Tunnel, J. Atmos. Ocean. Tech., 20, 781-790, 2003.

Twohy, C. H., DeMott, P. J., Pratt, K. A., Subramanian, R., Kok, G. L., Murphy, S. M., Lersch, T., Heymsfield, A. J., Wang, Z., Prather, K. A., and Seinfeld, J. H.: Relationships of biomass burning aerosols to ice in orographic wave clouds, J. Atmos. Sci., 67, 2437-2450, doi:10.1175/2010JAS3310.1, 2010.

Weber, R. J., Clarke, A. D., Litchy, M., Li, J., Kok, G., Schillawski, R. D., and McMurry, P. H.: Spurious aerosol measurements when sampling from aircraft in the vicinity of clouds, J. Geophys. Res., 103(D21), 28337-28346, 1998. 